\title{
RESISTÊNCIA BACTERIANA PELO USO INDISCRIMINADO DE ANTIBIÓTICOS: UMA QUESTÃO DE SAÚDE PÚBLICA
}

\section{BACTERIAL RESISTANCE FROM THE INDISCRIMINATE USE OF ANTIBIOTICS: A PUBLIC HEALTH ISSUE}

\section{RESISTENCIA BACTERIAL DEL USO INDISCRIMINADO DE ANTIBIÓTES: UN PROBLEMA DE SALUD PUBLICA}

\author{
Marcelo Oliveira ${ }^{1}$ \\ Kedina Damiana Silva Pereira ${ }^{2}$ \\ Cláudia Raquel Zamberlam ${ }^{3}$
}

\begin{abstract}
RESUMO: Os agentes antimicrobianos são de suma importância no tratamento de diversas infecções. No entanto, durante as últimas décadas, o uso indiscriminado e abusivo de antibióticos resultou no surgimento de uma nova preocupação no que tange a resistências de bactérias que não respondem mais à terapêutica antimicrobiana. As bactérias estão presentes em todos os ambientes, algumas são prejudiciais e outras essenciais no nosso dia a dia. Tais bactérias resistentes aos antibióticos trazem riscos afetando a saúde pública e alertando o mundo quanto a era pós- antibiótico onde a maior preocupação será em obter tratamentos eficazes para infecções simples que levarão pacientes a óbito. Assim, abordar a questão da resistência aos antibióticos é uma das prioridades mais urgentes em matéria de saúde pública nos dias de hoje, mobilizando órgãos públicos, governos, indústrias farmacêuticas, instituições de saúde para controlar sua evolução.
\end{abstract}

Palavras-chave: Resistência bacteriana. Saúde pública. Antibióticos.

ABSTRACT: Antimicrobial agents are of paramount importance in the treatment of various infections. However, over the past few decades, the indiscriminate and abusive use of antibiotics has resulted in a new concern for resistance of bacteria that no longer respond to antimicrobial therapy. Bacteria are present in all environments, some are harmful and some essential in our daily lives. Thus, addressing the issue of antibiotic resistance is one of the most urgent public health priorities today, mobilizing public agencies, governments, pharmaceutical industries, health institutions to control its evolution.

keywords: Drug Resistance Bacterial. Public Health. Anti-Bacterial Agents.

RESUMEN: Los agentes antimicrobianos son de suma importancia en el tratamiento de varias infecciones. Sin embargo, en las últimas décadas, el uso indiscriminado y abusivo de antibióticos

1 Graduando no curso de Farmácia da Universidade UNIVERITAS/UNG- campus ITAQUAQUECETUBA. Laboratório de Farmácia, setor de graduação. E-mail: platinilev@gmail.com.

2 Graduanda no curso de Farmácia da Universidade UNIVERITAS/UNG- campus ITAQUAQUECETUBA. Laboratório de Farmácia, setor de graduação. E-mail: kedna.pereira77@gmail.com.

3 Farmacêutica, Doutora em Ciências. Pós Doutorado em Neuropsicofarmacologia Molecular. Docente do curso de Farmácia da Universidade UNIVERITAS/UNG. Laboratório de Farmácia, setor de graduação. E-mail: crzamberlam@gmail.com. 
ha dado lugar a una nueva preocupación por la resistencia de las bacterias que ya no responden a la terapia antimicrobiana. Las bacterias están presentes en todos los ambientes, algunas son dañinas y otras esenciales en nuestra vida diaria. Por lo tanto, abordar la cuestión de la resistencia a los antibióticos es una de las prioridades de salud pública más urgentes hoy en día, movilizando a los organismos públicos, losgobiernos, las industrias farmacéuticas, las instituciones sanitarias para controlar su evolución.

Palabras clave: Resistencia Bacteriana aos Antibióticos; Salud pública; Antibacterianos. I INTRODUÇÃO

Em 1928, Alexander Flemming, biólogo e médico inglês, descobre a penicilina que no que lhe concerne foi observada através da substância que se movia no entorno do fungo ou colônia de Staphylococcus aureus, posteriormente chamada de Penicillium notatum, ele percebeu que o crescimento de outros micro-organismos era inibido, esse procedimento de inibição foi chamado de antibiose. Com isso, pela primeira vez foi possível combater bactérias que causavam infecções responsáveis pela taxa de mortalidade tão alta à época (GARCIA \& COMARELLA, 2018).

Contudo, com a descoberta dos antimicrobianos e a redução da taxa de mortalidade, o uso dos antibióticos cresceu levando a população a esse cenário de preocupação, pelo uso inadequado e indiscriminado destes fármacos, resultando numa resistência bacteriana tornando ineficazes diversos tratamentos e trazendo uma diversidade de problemas não somente aos pacientes e médicos, mas aos órgãos públicos, indústrias farmacêuticas e cientistas de todo o mundo, pois se tornou uma questão de saúde pública, afetando a saúde e a economia mundial, pela perda de produtividade.

Atualmente trata-se de um dos problemas de saúde pública mais preocupantes e de grande relevância é concernente a resistência bacteriana a antibióticos. Em um estudo feito por Jim O’Neil (2014), economista britânico, dez milhões de mortes ocorrerão ao ano em 2050, devido a resistência microbiana e esse impacto será grande na economia mundial, sendo de aproximadamente cem trilhões de dólares. (LOUREIRO et al., 2016; ESTRELA, 2018)

Devido à extrema necessidade em abordagens e soluções para esse assunto, em uma reunião da Assembleia Geral das Nações Unidas em 2or6, iniciou-se um comprometimento entre governantes e a partir de um conceito de Saúde Única (One Health), a Organização Mundial de Saúde incluiu a questão entre os dez maiores fatores ameaçadores à saúde em um plano estratégico. A Organização Mundial da Saúde (OMS) define AMR como a "capacidade de um microrganismo impedir a atuação de um antimicrobiano". (O’NEILL, 2014; OMS, 2015)

São muitos os motivos pelos quais nos deparamos com o uso indiscriminado dos antibióticos, tais como prescrições inadequadas, no que se refere a desnecessidade ou de amplo espectro com períodos e doses incorretas, quando poderiam ser prescritos de acordo com a 
realidade no caso do paciente. A falha na comunicação entre médico e paciente também se enquadra nesse contexto e tratamentos que poderiam ser de curto prazo, tornam-se problemas, às vezes até mesmo irreversíveis. (ESTRELA, 2018)

O tema proposto neste artigo é de suma importância para o nosso momento, tendo em vista que os Antibióticos vieram para solucionar diversas doenças que por décadas levaram milhares de pessoas ao óbito. Em meio a pandemia do Corona Vírus, o tema ainda segue em debate como uma das prioridades mundiais. Em uma coletiva de imprensa, o chefe da Organização Mundial de Saúde (OMS), Tedros Adhanom Ghebreyesus afirmou que "a resistência aos antimicrobianos não parece tão urgente como uma pandemia, mas é igualmente perigosa". (OMS, 2020)

De acordo com a OMS "o fenômeno mundial da resistência antimicrobiana, é tão perigoso quanto uma pandemia, ameaça destruir um século de progresso médico", alertou a Organização Mundial da Saúde (OMS, 2020; OMS, 2015).

Portanto, com o uso descontrolado de Antibióticos e com a resistência de bactérias, enfrentamos o momento em que se não discutirmos e enriquecermos nossos estudos sobre o assunto de maneira a inibir o uso indiscriminado desses fármacos, viveremos em uma era onde não haverá mais antibióticos eficientes e a ciência da saúde precisa estar pronta para isso.

Nesse período mencionado, enfrentaremos novamente índices altos de óbitos, porém, de casos mais brandos e, infelizmente, com isso a economia não terá que se preocupar apenas com a perda de produtividade, mas com fatores mais agravantes que atingirá toda a população mundial.

Diante deste cenário, o presente artigo pretende apresentar as discussões acerca do uso indiscriminado os antibióticos e a evolução das resistências e explicitar diante dos marcos no contexto mundial, as medidas brasileiras para contribuir com o enfrentamento desse problema.

\section{METODOLOGIA}

O presente estudo realizou uma revisão de literatura sobre a resistência bacteriana pelo uso indiscriminado de antibióticos e seu impacto na saúde pública. Para o desenvolvimento do estudo, foram utilizados os bancos de dados Scientific Electronic Library Online- SCIELO e Google Acadêmico, para realizar as buscas de artigos científicos publicados no período de 2015 a 2020, período esse utilizado como critério de inclusão.

Para a seleção de artigos foram utilizados os seguintes descritores: uso irracional de antibióticos; resistência bacteriana; saúde pública; antibióticos.

Nestes bancos de dados foram encontrados 49r artigos. A partir da primeira seleção, de acordo com a leitura de resumos e conseguinte a leitura do conteúdo na íntegra foram filtrados 
artigos que obtivessem os mesmos objetivos deste artigo de revisão. Foram selecionados 58 artigos e publicações em revistas pertinentes ao assunto para embasarem o presente estudo. Os artigos originais utilizados totalizam-se em in e artigos descritivos somam- se em 44 para a realização da pesquisa.

\section{REVISÃO BIBLIOGRÁFICA}

4.I $\mathrm{O}$ uso indiscriminado de antibióticos e sua relação com o surgimento de bactérias resistentes

Os antibióticos são utilizados para combater bactérias e no tratamento de doenças provocadas por elas. De acordo com a definição de origem grega, a palavra antibióticos, sendo "anti" (contra) e "bio" (vida), é um composto para combater vida, todavia estamos nos referindo a vida bacteriana. (ANVISA, 2018; GARCIA, 2019; COSTA \& SILVA, 2017)

Podem ser compostos de origem natural ou sintético podendo impedir a evolução das bactérias, neste caso sendo bacteriostáticos, ou podem eliminá-las de fato matando-as, isto chamamos de bactericidas, neste caso nenhuma das situações causam danos ao hospedeiro. (MARQUES \& DEUSCHLE, 2015)

Desde a descoberta dos antibióticos pelo médico inglês Flemming, os tratamentos de doenças infecciosas, na época doenças que resultavam a morte de milhares de pessoas no mundo, se tornaram eficazes diminuindo significativamente a taxa de mortalidade em diversos países. (COSTA \& SILVA, 2017; RODRIGUES et al., 2017)

Com isso, os antibióticos tornaram-se os medicamentos mais utilizados pelos serviços de saúde, porém há critérios indispensáveis no uso desses medicamentos para que o tratamento de fato seja eficaz, como é o caso de haver dentro de uma célula bacteriana um alvo a ser atingido e a substância do antibiótico deve ser na dosagem correta para alcançar esse alvo, não podendo inativar ou modificar a estrutura do fármaco. (RODRIGUES et al., 2017; COSTA, 2016)

Com o uso inadequado e excessivo dos antibióticos surgem as superbactérias, visto que são bactérias resistentes a eles, sendo subdividas em multirresistentes, extensamente resistentes ou pan-resistentes. O primeiro se dá ao fato de serem resistentes a um antibiótico de três ou mais classes distintas. O segundo são as resistentes a apenas uma ou duas classes e por fim as panresistentes são resistentes a todos os antibióticos de todas as classes não havendo antibióticos eficientes para este caso. (SILVA, 2017)

A resistência bacteriana pode ser classificada como intrínseca (natural) e adquirida. No caso da resistência intrínseca ou natural, entende-se como aquela que é herdada geneticamente por suas próprias características. Por outro lado, a "adquirida", como seu próprio nome explica, é aquela adquirida por fatores externos, como é o caso do uso irracional de antibióticos. (SOUZA, 2016) 
Além disso, a resistência bacteriana traz uma grande preocupação para a saúde pública, inclusive no que tange ao SUS, tendo em vista custos elevados partindo do princípio de que aumentam o número de consultas, automaticamente é necessário um quadro maior de profissionais contratados evitando uma superlotação em hospitais, demandam exames diagnósticos, novas prescrições, internações e consequentemente novos leitos. (SOUZA, 2016)

Outra informação de extrema relevância trata da intoxicação medicamentosa, que, é um risco quando falamos em uso irracional de medicamentos. De acordo com o Sistema Nacional de Informações Tóxico Farmacológicas (SINTOX), os medicamentos estão entre os primeiros agentes no que diz respeito a intoxicação no ano de 2013, já no ano de 2015 este número subiu para 24.549 casos, sendo ainda a primeira causa de intoxicação no Brasil devido ao consumo em dosagem acima do indicado a facilidade de acesso aos medicamentos. (CFF, 2018; SINTOX, 2013)

De acordo com Keiji Fukuda, subdiretor-geral da OMS, o mundo prossegue para uma era pós-antibióticos, na qual infecções correntes e feridas menores, que durante décadas eram curadas com facilidade, podem voltar a matar", adverte. (OMS, 2020).

No ano de 20II, a Organização Mundial de Saúde (OMS), afirmava que esse seria uma ameaça a população, porém desde o ano de 2014 a OMS vem afirmando que a resistência bacteriana não é mais apenas uma mera ameaça, mas uma realidade, afirmando isso em um relatório em escala mundial (Global Strategy for Containment of Antimicrobial Resistance) alertando que esta ameaça não é mais uma previsão, e sim uma realidade que afeta a todos, independentemente da idade ou país de origem. (OMS, 2018)

Segundo Suzanne Hill, diretora do Departamento de Medicamentos Essenciais e Produtos de Saúde da OMS, "o uso em excesso e inadequado de antibióticos é a principal causa de resistência antimicrobiana" e sem os tratamentos eficazes com esses medicamentos, as infecções comuns não serão devidamente tratadas. Entre 2000 e 2010 foi de $36 \%$ o aumento do consumo de antibióticos em 7I países e dentre os responsáveis por pelo menos 3/4 (três quartos) do aumento estava o Brasil. (OMS, 2018; BOECKEL, 2014).

Outro fator preocupante está relacionado ao uso de antibióticos em animais, as pesquisas apontam que esse consumo no Brasil e em outros países desenvolvidos duplicará até o ano de 2030. Para acelerar o crescimento de animais que serão destinados ao consumo humano, são utilizados antibióticos e essa é uma das maiores preocupações no setor agrícola econômico podendo ser interpretada como uma preocupação disfarçada de ordem sanitária, pois nesses casos as importações de carnes medicadas não terão o mesmo impacto, tendo em vista suas restrições, diminuindo, portanto, os lucros obtidos por eles. (ROBINSON et al., 20I5; O'NEILL, 2014).

Nesse sentido, Keiji Fukuda, para a segurança alimentar, adverte que "se não adotarmos medidas significativas para prevenir melhor as infecções e modificar a forma como produzimos, 
prescrevemos e utilizamos os antibióticos, vamos perder pouco a pouco estes benefícios da saúde pública mundial e as consequências serão devastadoras". (OMS. 2020).

No cenário atual, a preocupação da OMS é a crescente tendência do uso de antibióticos neste período de pandemia de COVID-19. A organização menciona que "as evidências mostram que apenas uma pequena proporção de pacientes com COVID-I9 precisa de antibióticos para tratar infecções bacterianas subsequentes" e orienta que não seja utilizado antibioticoterapia aos pacientes infectados pelo vírus, exceto situação adversa e necessária. (OPAS, 2020).

Considerando a possibilidade de tratamento com medidas eficazes sem a necessidade de antibióticos, de acordo com o diretor-geral assistente de resistência antimicrobiana da OMS, "esta orientação clara sobre o uso de antibióticos na pandemia de COVID-ig ajuda os países a combater a doença de maneira eficaz e evitar o tratamento e a transmissão da resistência antimicrobiana no contexto da pandemia "afirma Hanan Balkhy. (OPAS, 2020)

4.2 A indústria farmacêutica e seus desafios relacionados aos microrganismos

Um dos maiores desafios no enfrentamento a Resistência Bacteriana é a adaptação dos mecanismos de forma célere, deixando em evidência que o desenvolvimento em novas tecnologias não tem conseguido acompanhar esses avanços. Ainda, as empresas não têm investido maiores esforços na produção de novos antibióticos, pois não há retorno lucrativo, além do desabastecimento de penicilina afetando diversos países, dentre eles, o Brasil.

Além de longos anos de pesquisa para a fabricação de um medicamento antibiótico que em breve se tornará inutilizado devido a resistência bacteriana, outra desvantagem existente trata-se do retorno financeiro que é insuficiente para cobrir os gastos obtidos no processo de pesquisa e estudo.

Com isso, é importante ressaltar que doenças infectocontagiosas antes já controladas, possivelmente serão enfoques novamente na saúde pública, como é o caso da febre amarela, malária, doença de chagas, esquistossomose, hanseníase, tuberculose, entre outras (SILVA, 2018).

4.3 Portaria n.ํㅜ 344/1998, RDC 20/201r e Planos de Ação

A Portaria 344 de 12 de maio de 1998, aprova o Regulamento Técnico sobre substâncias e medicamentos sujeitos ao Controle Especial. Os parâmetros do fim que será dado ao medicamento e substâncias especiais são determinados por ela. No ano de 2010, a ANVISA em audiência pública propôs a inclusão dos antibióticos na lista de medicamentos e substâncias da Portaria 344/ 98 requerendo: Receita de Controle Especial em duas vias; Apresentação e Retenção de uma via da receita no ato da dispensação; dizeres de rotulagem e bula apresentando a seguinte 
frase: "VENDA SOB PRESCRIÇÃO MÉDICA - SÓ PODE SER VENDIDO COM RETENÇÃO DA RECEITA". (BRASIL, ANVISA, 2014; 2018).

$\mathrm{Na}$ época das propostas o diretor-presidente da ANVISA, Dirceu Raposo de Mello, afirmou que "o uso indiscriminado de antibióticos é um problema de saúde pública em todo o mundo. A ideia é que o controle sobre esses medicamentos seja feito de forma efetiva, contribuindo para o consumo racional desses produtos", e mencionou a sobre a importância de farmacêuticos, sociedades médicas, indústria farmacêutica, autoridades sanitárias e população atuarem no controle de consumo dos antibióticos. (BRASIL, ANVISA, 2014; 2018).

Nesse período, surge a informatização dos registros de venda de medicamentos, passando a substituir a escrituração manual que era realizada em livros, com isso a tendência era ampliar a lista de medicamentos da Portaria 344/98, incluindo os antibióticos. Assim foi elaborada pela ANVISA e publicada a Resolução de Diretoria Colegiada (RDC) n. 020 de 25 de julho de 20II, que, por sua vez, revogou a RDC n.ำ 44 de 17 de agosto de 2010 . A RDC n.ำ 20 é criada estabelecendo a inclusão dos antibióticos no Sistema Nacional de Gerenciamento de Produtos Controlados (SNGPC) e a obrigatoriedade de retenção de receita, seja em farmácias públicas ou privadas.

O objetivo da RDC n. 20 seria controlar a venda de medicamentos antibióticos dificultando o fácil acesso de pacientes a estes fármacos inibindo a automedicação. (CORRER \& OTUKI, 2013)

Apesar da criação da Resolução, ainda há o desconhecimento da população a respeito da referida RDC e diante desse fato a preocupação é baseada na possibilidade do não cumprimento efetivo da norma, não bastando a legislação para o controle do uso indiscriminado de antibióticos, resultando na continuidade de evolução e multiplicação das resistências bacterianas (SAMPAIO, 2018)

Ao nível mundial, no ano de 20II, a preocupação com a problemática aumentava cada vez mais, nesse período a OMS apresentou um pacote de estratégias políticas para o combate da Resistência Bacteriana, todavia ainda era necessária à coleta de dados reais e relevantes para compreender a realidade sobre o assunto. Após esse entendimento, em 2013 foram reunidos 133 países membros, para analisarem seu perfil e suas iniciativas acerca do tema. Assim, no referido ano foi constituído o Grupo Consultivo Estratégico e Técnico em Resistência Antimicrobiana (STAG-AMR), composto por diversas equipes e contando com especialistas em saúde pública. Com a evolução em suas pesquisas desenvolveram "Plano de Ação para Resistência Antimicrobiana”, o chamado embrião para um Plano de Ação Global, assim elaboram o seguinte documento em 2014, "Resistência antimicrobiana: relatório global sobre vigilância", apresentada 
pela primeira vez ao nível global a importância do tema para a saúde pública no mundo (ESTRELA, 2014).

Com os dados analisados, viu-se a necessidade da elaboração de um Plano de Ação Global partindo do princípio de uma abordagem de Saúde Única. No ano de 2015, após constatado que poucos países possuíam planos sobre a Resistência Antimicrobiana, durante a 68. a Assembleia Mundial de Saúde, os Estados-membros da OMS elaboraram, por meio da Resolução WHA 68.20, o "Plano de Ação Global para o Enfrentamento à Resistência aos Antimicrobianos", em parceria com a Organização das Nações Unidas para Alimentação e Agricultura (FAO) e a Organização Mundial da Saúde Animal (OIE) que tinham por objetivo maior conhecimento sobre a Resistência Bacteriana, fortalecer a vigilância epidemiológica, combater infecções, racionalizar o uso de medicamentos antimicrobianos na saúde humana e animal e garantir investimento sustentável para sua implementação (ESTRELA, 2014).

Vale ressaltar que, no Brasil as ações de prevenção foram iniciadas antes mesmo do Plano de Ação Global de 2015, como é o caso do Programa de Controle de Infecções Hospitalares foi instituído no ano de 1998 considerado um marco no aspecto de saúde humana no que diz respeito as infecções hospitalares no Brasil. Esse programa tinha como objetivo reduzir a gravidade dessas infecções com a qualificação da assistência hospitalar e vigilância sanitária mencionando pela primeira vez sobra o uso racional de medicamentos, germicidas e materiais hospitalares (ESTRELA, 2014)

Tivemos também a Rede Nacional de Monitoramento da Resistência Microbiana em Serviços de Saúde que foi realizada no ano de 2005 pelo Ministério da Saúde e ANVISA em parceria com a OPAS com o intuito de obter maior detecção, prevenção e controle da emergência de resistência nos serviços de saúde. (ESTRELA, 2014)

4.4 A Atuação do profissional da saúde frente ao atendimento do paciente 4.4.I. Atenção e assistência farmacêutica nas prescrições médicas

Um estudo apresentado no congresso da Sociedade Espanhola de Médicos de Atendimento Primário (Semergen), em Palma de Mallorca, estudo esse que reúne I20 respostas, mostrou que médicos, ainda que em sua minoria, dizem: "às vezes, prescrevo antibióticos porque os pacientes me pedem"; também "por falta de tempo para explicações"; e para que "continuem confiando em mim”. Esse estudo alerta para considerável melhoria no centro de saúde, justificando um Programa de Otimização do Uso de Antibióticos. (GÜELL, 2018)

Quando há infecção com bactéria resistente, as opções de novos tratamentos com medicações se tornam severamente escassas, fazendo com que aquele paciente permaneça por mais tempo hospitalizado, isso com certeza estará gerando custos maiores, por fim o paciente 
estará ainda mais exposto a inúmeros tipos de infecções hospitalares e este com certeza não é uma agravante que auxiliará em sua recuperação, tampouco no combate a resistências bactérias (SANTIAGO et. al, 2020).

Em contrapartida, temos os pacientes que estão em busca de antibióticos com uma falsa ideia de que apenas com eles adquirirão um tratamento mais célere e eficaz. Esses pacientes costumam fazer a solicitação de prescrição de antibióticos aos médicos, que por sua vez, cedem ao pedido por insegurança ou por não conhecer mais a fundo a doença no caso concreto daquele paciente (SANTIAGO et. al, 2020).

PAIM et al., (2014), relata que em resultados de um determinado estudo onde houve a implementação de um programa educativo sobre o uso racional de medicamentos antimicrobianos, houve também a redução de prescrições médicas de antimicrobianos, demonstrando, portanto, que a cooperação entre os profissionais somados ao incentivo de um consumo adequado, otimiza o tratamento de um paciente e consequentemente, previne problemas imensuráveis na saúde pública.

A atenção farmacêutica deverá ser de maneira responsável e totalmente humanizada com o cuidado na prevenção de erros, pensando nesse aspecto o Programa Nacional de Segurança ao Paciente e criado com o objetivo de prevenir situações atípicas ao que se deve esperar do atendimento oferecido pelo farmacêutico ao paciente. (BRASIL, 2014)

FRANCO et al., (2015), acreditam que ainda há muito para se realizar no setor privado e público, considerando que no setor público uma boa e efetiva atenção farmacêutica fará com que haja uma redução nos custos e melhora na qualidade de vida, por outro lado, no setor privado haverá uma melhora significativa despertando a confiança dos pacientes, fidelizando-os.

O estudo de Oliveira e colaboradores (2019), ressalta que, na prática, as atribuições de medicação são de responsabilidade do profissional farmacêutico, porém o profissional de enfermagem é treinado para a diluição e administração de medicamentos. Nesse sentido o farmacêutico deverá cooperar com sua equipe treinando-os para que falhas no atendimento sejam evitadas (FRANCO et al., 2015)

A Assistência Farmacêutica é entendida por seu conjunto de ações e serviços visando assegurar a assistência terapêutica integral e a promoção, a proteção e a recuperação da saúde, tendo o insumo essencial, qual seja o medicamento, o acesso e seu uso racional. (CFF, 2013)

O farmacêutico, porém, deve se manter atualizado sobre os adendos da lista de substâncias e medicamentos de controle especial da Portaria 344/98. Portanto, se entende que, o farmacêutico é o profissional na área da saúde que mais é acessível ao público, devendo sempre aconselhamento a seus pacientes, uma vez que na assistência farmacêutica deve haver estratégias de selecionar uma melhor terapia medicamentosa (CFF, 2013) 
Com isso, também o artigo 20 da Resolução do Conselho Federal de Farmácia (CFF) n.o 357/200I dispõe que "a presença e atuação do farmacêutico é requisito essencial para a dispensação de medicamentos aos pacientes, cuja atribuição é indelegável, não podendo ser exercida por mandato nem representação" (CRF, 2017)

Ademais, o tópico 6.I do Manual De Orientação Ao Farmacêutico, dispõe sobre a dispensação de medicamentos reafirmando que o papel do farmacêutico é fundamental no combate ao uso irracional, infecções e resistência bacteriana, reforçando a importância do farmacêutico conhecer a RDC n. ${ }^{\circ}$ 20/20II.

No que tange a prescrição, de acordo com a RDC n.을 20/20II, deverá ser realizada por profissionais legalmente habilitados e escritos de forma legível, sem rasuras e em duas vias.

A I. ${ }^{a}$ via é devolvida ao paciente com comprovação do atendimento mediante anotação e a 2. a via ficará retida. Algumas informações são obrigatórias na receita, ainda que não haja um modelo padrão como demonstra a figura a seguir:

Figura r:Modelo de Prescrição de antibióticos

\section{IDE}

Identificação do

Nome completo do paciente, idade e sexo

Contato

nome do medicamento prescrito sob a forma de $D C B$, concentração, forma farmacêutica, dose, frequência e duraçâo do tratamento, quantidade a ser fornecida, orientação sobre o uso correto do medicamento e instruções adicionais

Nome completo do prescritor

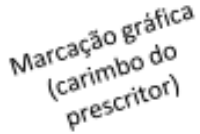

Assinatura

NQ registro profissional

local e data

Endereço completo do estabelecimento ou consultório e telefone

Fonte: Manual de Orientação ao Farmacêutico (2017)

Ressalta-se que não poderá ser dispensados os medicamentos em cujas receitas há rasuras e letras ilegíveis que induzam ao erro. Por fim, o farmacêutico ética e moralmente deve ter como 
objetivo assistência segura para com seus clientes, assim como devem possuir conhecimento científico devidamente amparado, normas legais regulamentando seus direitos e deveres no exercício de sua profissão, além de manter-se atualizado acerca dos adendos de medicamentos em legislações. (CRF, 2017).

4.4.2. Uso racional de medicamentos e ações de combate e enfrentamento a resistência bacteriana

A Organização Mundial da Saúde relata que ocorre o uso racional de medicamentos quando: "Os pacientes recebem medicamentos apropriados para suas condições clínicas, em doses adequadas as suas necessidades individuais, por um período adequado e ao menor custo para si e para a comunidade". (OMS, 1985 ).

Os medicamentos administrados na dosagem correta, de uso racional, respeitando o tratamento indicado, são considerados essenciais para que a saúde do ser humano seja garantida, tendo em vista que medicamentos serão utilizados em algum momento de nossas vidas, (OLIVEIRA, 2018; CAVEIÃO, 2016)

Para combater e enfrentar o uso indiscriminado de antibióticos e consequentemente a Resistência Bacteriana, um dos primeiros passos está relacionado a prescrição médica correta do medicamento ao paciente, para que isso aconteça há a necessidade de uma boa formação dos profissionais médicos que serão um dos primeiros a presenciar a situação do paciente e investigar seu caso. Necessário se faz a revisão de 2 a 3 dias do quadro clínico e exame microbiológico do paciente (OMS, 2015)

Entende-se que para que o tratamento seja eficaz, o paciente necessariamente precisa de fato compreender como deverá proceder seu tratamento, pois o paciente bem informado acerca dos riscos do uso indiscriminado e desnecessário de um medicamento antibiótico, terá a liberdade para questionar seu médico sobre a real necessidade do uso do medicamento, questionando inclusive sobre o período e dosagem, evitando que haja a possibilidade de prescrições desnecessárias.

Ao passo que houve a identificação da real necessidade do tratamento com antibióticos, acreditando que o paciente esclareceu suas dúvidas acerca do tratamento com seu médico, iniciase a importância do trabalho multidisciplinar entre médico, enfermeiro e farmacêutico para a prevenção da resistência bacteriana (PAIM et al., 2014).

Em tese o paciente contata o farmacêutico após consulta com médico, tornando o profissional farmacêutico o corresponsável por este paciente. Como já vimos o farmacêutico, moral e inclusive por Lei possui um compromisso consolidado de modo a assegurar a saúde do paciente. Este deverá manter-se atualizado quanto às resoluções em vigência, não deixando de 
realizar seu trabalho com amplo atendimento responsável, humano, sempre preservando e acompanhando o tratamento do paciente (PAIM et al., 2014; ANGONESI, 2010)

A Resolução n. ${ }^{585}$ / 2013 do Conselho Federal de Farmácia em seu artigo 8으 dispõe acerca das atribuições do farmacêutico no que tange a Educação em Saúde, nesse sentido SOUZA (2017) menciona sobre a importância do envolvimento do farmacêutico em Campanhas sobre o uso racional de medicamentos, pois assim os pacientes têm a possibilidade de adquirir conhecimento sobre os cuidados no consumo e os riscos da automedicação.

No que tange a legislação, a OPAS (2008) recomenda que seja atualizada periodicamente, contando com a presença de farmacêuticos com conhecimentos especializados para a elaboração de novos projetos de lei, bem como a revisão daquelas que estão vigentes.

Entretanto, não bastando a educação em saúde da população para aprimorar o conhecimento a respeito do uso racional de medicamentos SILVA (2017) menciona sobre a importância na educação em saúde, porém com o foco na saúde animal, considerando que é necessário monitoração na utilização desses medicamentos na produção animal para consumo, em relação à vacina e higienização nos animais para a prevenção de infecções, por fim o uso de antibióticos próprios apenas em caso de uso terapêutico.

Outras soluções advêm de medidas políticas, visto que são de extrema relevância em modificações que poderão ser significativas para a sociedade, como, por exemplo, apoiando novas tecnologias, incentivos às indústrias farmacêuticas; desenvolvendo novas ferramentas de controle mais efetivas não somente de venda, mas na prescrição e uso de antibióticos. (ROCA et al., 2015).

Em relação às indústrias farmacêuticas, SILVA (2017) apud Roca et al., (2015) acredita que há necessidade de desenvolvimento de novos antibióticos, porém mais eficazes e testes rápidos para que haja uma identificação célere no momento da consulta do médico ao paciente, com o intuito de vislumbrar as bactérias em questão e sua suscetibilidade ao antibiótico, fazendo com que a prescrição seja mais exata para o tratamento do paciente.

Portanto, tendo em vista que inicialmente os antibióticos na maioria dos casos, são administrados inadequadamente e sem o conhecimento prévio acerca do patógeno da infecção, a consequência é automaticamente a falha no tratamento e consequentemente a resistência bacteriana podendo inclusive levar a mortalidade, por essa razão o Ministério da Saúde defende que inicialmente deve-se identificar as espécies de cada microrganismos para que haja um tratamento correto e eficaz. (ROCHA, 2014)

Evidente que, essas são apenas algumas medidas dentre tantas outras a serem tomadas, porém, de acordo com os estudos realizados, são medidas que se colocadas em prática trarão 
resultados positivos no enfrentamento ao uso indiscriminado de antibióticos e suas consequências.

\section{RESULTADOS E DISCUSSÃO}

Após realizada a coleta do material didático e a leitura dos documentos em comento, verificou-se que os antibióticos são utilizados de diversas maneiras que podem ser consideradas como irracionais, como é o caso do uso para o tratamento de doenças não infecciosas e febris e aqueles cujo sua dosagem excede ou falta para atingir o alvo a ser combatido. Desta mesma forma entendem os demais autores, corroborando uns com os outros.

Ainda que, diversas iniciativas recentes foram elaboradas e estejam vigorando para o combate e enfrentamento da Resistência Bacteriana, para ESTRELA (2018), as soluções ainda não parecem suficientes para mensurar a gravidade e impacto das infecções, tanto na saúde humana, quanto na saúde animal.

No mesmo sentido, SOUZA (2016) menciona que diante do número crescente de drogarias e farmácias a fiscalização torna-se mais complexa nesses estabelecimentos, demonstrando em pesquisas que a RDC 20/II controla a venda de antibióticos, todavia após 5 anos de sua publicação os resultados não demonstram ser tão eficazes, visto que o controle de prescrições não é igualmente fiscalizado.

Com base nesse entendimento, podemos avaliar que as medidas públicas e legais deverão ser ainda mais rigorosas, tendo em vista que abrem brechas para que o uso indiscriminado continue existindo dificultando o enfrentamento da questão.

Para MUNER (2020), após o estabelecimento da Portaria, os medicamentos se tornaram mais fiscalizados, porém apesar de seu estudo constatar a veracidade do maior controle de medicamentos de forma irregular, ainda deve existir maior efetividade na fiscalização, leis e trabalho em conjunto entre os profissionais da saúde de modo a sanar desvios de conduta.

Assim analisamos também que a conduta do farmacêutico deve ser integra apesar de Medidas Governamentais, visto que seu compromisso é assegurar a saúde e qualidade de vida do paciente.

Em se tratando de automedicação, nota-se que os autores seguem o entendimento de que este é um dos fatores determinantes para a contribuição no aumento de bactérias resistentes aos antibióticos. BUENO (2017), aponta que no Brasil em média 35\% dos medicamentos adquiridos são por automedicação. Além disso, para FRANCO et. al., (2015), a necessidade de maior contribuição para o combate ao uso indiscriminado se relaciona diretamente com a preocupação de haver grandes prejuízos nos setores privados e públicos, como aumento nas internações e em taxas de infecções hospitalares. 
Portanto, ambos os autores em seus estudos avaliam que a existência de uma prescrição correta, impedindo assim automedicação, ou a participação do profissional da saúde na orientação desse paciente, além de preservar a vida deste paciente, impede com que outras vidas sejam afetadas, diminuindo os prejuízos no setor público e privado, desafogando, portanto, outros setores como o industrial, econômico e agrícola.

Para FRANCO et al., (2015), o papel do farmacêutico é de responsabilidade social, tendo em vista que é o responsável pela melhoria de qualidade de vida do paciente evitando problemas com medicamentos por meio da farmacoterapia adequada para cada caso.

REGINATO (2015), prossegue entendendo que além dessa função social, o farmacêutico é essencial na conscientização do uso racional dos antibióticos, avaliando os erros e interações medicamentosas prescritos, mantendo uma relação com outros profissionais, no intuito de criar uma corrente de auxílio diminuindo o índice de erros nas prescrições.

Portanto, podemos analisar que a participação do profissional farmacêutico está diretamente relacionada com a saúde pública, visto que são um dos maiores responsáveis por orientar e conscientizar a população sobre o uso racional dos medicamentos.

Notou-se também comum entendimento no que tange a importância do profissional farmacêutico no momento da prescrição. Para GARCIA (2019), os prejuízos de uma prescrição incorreta são vários, dentre eles, está o fato de o paciente necessitar da medicação correta, por vezes devendo retornar ao médico, que deverá prescrever novamente uma receita, analisando de maneira complexa, o paciente poderá ter dificuldades em remarcar uma consulta médica, principalmente em se tratando de médicos no SUS.

SOUZA (2017), menciona que o profissional é essencial na orientação quanto a gravidade da prática da automedicação, alertando sobre os riscos de agravamento de doenças, surgimento de bactérias resistentes, podendo levar o paciente a morte.

Ressalta que na assistência farmacêutica a intervenção de uso indiscriminado é fundamental, devendo o farmacêutico atuar na prescrição e dispensação, além disso, atuar na educação em saúde, cooperando para a evolução na saúde do paciente e qualidade de vida.

Outro fator considerado relevante acerca do papel do farmacêutico, está relacionado ao ato de identificação do agente infeccioso. FRANCO et al., (2015), esclarece que, o exame como o antibiograma é essencial, tendo em vista a possibilidade de atuar de maneira mais eficaz no caso do paciente.

Diante dos estudos mencionados, não há como não evidenciar que as pesquisas corroboram no sentido de demonstrar que a gravidade do problema é de nível global, necessitando de um trabalho multidisciplinar amplo e eficácia das normas regulamentando desde 
o procedimento do atendimento clínico- hospitalar ao momento em que efetivamente se iniciará o tratamento medicamentoso desse paciente.

Restando que os profissionais na área da saúde mantenham conhecimento atualizado e conduta direcionada assegurar a efetividade na saúde pública unindo seus esforços para que a atenção farmacêutica e assistência farmacêutica ocorra como proposta.

\section{CONSIDERAÇÕES FINAIS}

A resistência bacteriana resultante do uso indiscriminado sempre será uma questão grave de saúde pública, porém para que possamos ao menos manter o mínimo controle em face desse problema mundial, é necessário cada vez mais profissionais cientes deste mal e cada vez mais responsáveis em suas atribuições no dia a dia de seu ofício para com os pacientes. Ainda assim, não será a solução completa, pois, é necessário que os órgãos públicos estejam cada vez mais engajados em seu papel informativo e com medidas normativas muito mais eficientes para que a população tenha consciência do alto risco na automedicação e se tornem ativos no combate ao uso irracional e indiscriminado desses fármacos.

Podemos concluir que há uma urgência no que diz respeito a atuação responsável e ativa do profissional farmacêutico tendo em vista ser um dos profissionais indispensáveis no tratamento do paciente, evitando que estes realizem o uso de antibióticos de maneira inadequada e dando-lhes a consciência de que não se trata de uma problemática individual, mas de saúde pública em alcance global.

Acredita-se que os custos na saúde pública serão maiores no decorrer dos anos se considerarmos que as indústrias farmacêuticas perderão ainda mais o interesse em investimentos para a fabricação de novos antibióticos o que poderá causar um acúmulo de internações ainda maiores nos hospitais.

Todavia, em sugestões de medidas preventivas são incluídos o incentivo às indústrias farmacêuticas, amplitude em tecnologias para a criação de identificadores de bactérias para a utilização anterior a tratamentos medicamentos e com base na educação em saúde, o incentivo de maiores campanhas sobre o uso racional de antibióticos, incluindo a participação ativa dos profissionais farmacêuticos em projetos de leis, na comunidade, no treinamento de sua equipe, etc.

Por fim, com o presente estudo concluímos que há muito o que ser feito para que este caos não ocorra ou que ao menos seja minimizado. Ademais, a muito estudo e pesquisa a ser realizado para compreender o que poderá ser desenvolvido cientificamente e biologicamente acerca do surgimento de inúmeras novas bactérias e consequentemente planos para que os setores 
públicos/privados, econômico, agrícola entre outros estejam cada vez mais preparados para o enfrentamento da Resistência Bacteriana pelo uso indiscriminado de Antibióticos.

\section{REFERÊNCIAS}

ALFAYATE M. S, GARCIA-MARCOS L. Uso racional de antimicrobianos no tratamento de infecções das vias aéreas superiores. J. Pediatr. (Rio J.) [Internet]. 2020 Mar [citado $2020 \mathrm{abr}$ 29]; 96 (Supl. I): III-II9. Disponível em: http://www.scielo.br/scielo.php?script=sci_arttext\&pid=So021-75572020000700m\&lng=en. Epub i7 de abril de 2020. https://doi.org/ro.ror6/j.jped.2019.11.oor.

ANGONESI D \& SEVALHO G. Atenção Farmacêutica: fundamentação conceitual e crítica para um modelo brasileiro. Ciênc. saúde coletiva [Internet]. 2010 Nov [citado 2020 Nov 26] ; I5(3): 3603-3614. Available from: http://www.scielo.br/scielo.php?script=sci_arttext\&pid=SI4I381232010000900035\&lng=en. http://dx.doi.org/10.1590/SI413-81232010000900035.

BOECKEL, VT et al. Global antibiotic consumption 2000 to 20ro: an analysis of national pharmaceutical sales data. The Lancet infectious Diseases, New York, v. I4, n.8, Ag. 2014

BRASIL. Agência Nacional de Vigilância Sanitária (ANVISA). Semana Mundial De Uso Consciente De Antibióticos. [internet] 2018 Nov [citado 2020 Abr 25]: Disponível em: http://portal.anvisa.gov.br/antibioticos.

BRASIL. Ministério da Saúde. Organização Mundial de Saúde. O uso excessivo e inadequado de antibióticos é principal causa de resistência antimicrobiana (Brasil). Ministério da Saúde, 2018. [internet]2018 Nov [citado em 2020 Abr 22]: Disponível em: https://nacoesunidas.org/oms-uso-excessivo-e-inadequado-de-antibioticos-e-principal-causade-resistencia-antimicrobiana/

BRASIL. Ministério da Saúde. Programa Nacional de Segurança do Paciente; Ministério da Saúde; Fundação Oswaldo Cruz; Agência Nacional de Vigilância Sanitária. - Brasília: Ministério da Saúde, 2014. 40 p.: il.

BRASIL. Organização Pan-Americana de Saúde (OPAS). Número recorde de países contribui com dados que revelam taxas preocupantes de resistência antimicrobiana. [Ide junhode2020]https://www.paho.org/bra/index.php?option=com_content $\&$ view $=$ article $\&$ id $=6 \mathrm{I}$ 87:numero-recorde-de-paises-contribui-com-dados-que-revelam-taxas-preocupantes-deresistencia-antimicrobiana\&Itemid $=8 \mathrm{I} 2$.

BUENO F. Uso irracional de medicamentos: um agravo à saúde pública. [internet] 2017 [citado em 2020 Ago 22]. 39 f. [Monografia]. Universidade Regional do Noroeste do Estado do Rio Grande do Sul. Disponível em: http://bibliodigital.unijui.edu.br:808o/xmlui/handle/123456789/4499.

CORRER C.J. \& OTUKI M.F. A Prática Farmacêutica na Farmácia comunitária. Liv. Edi. Artmed Editora [Internet] 2013 [citado 2020 Out 09]. Disponível em: <iframe frameborder="o" scrolling="no"style="border:opx" src="https://books.google.com.br/books?id=qHoSS 70 R $7 \mathrm{dQC}$ $\& \mathrm{lpg}=\mathrm{P} \mathrm{PI}_{2} \& \mathrm{hl}=\mathrm{pt}-\mathrm{BR} \& \mathrm{pg}=\mathrm{PP}_{2} \&$ output $=$ embed" width=500 height $\left.=500\right\rangle /$ iframe $>$; pagina 94-95.

CONSELHO FEDERAL DE FARMÁCIA (CFF). O papel do farmacêutico no Sistema de Atenção à Saúde. CFF, 2010. [Internet] 2010 Jan [citado 22 Ago]. Disponível em: 
https://www.paho.org/bra/index.php?option=com_docman\&view=document\&layout=default \&alias=748-o-papel-do-farmaceutico-no-sistema-atencao-a-saude-ategory_slug=medicamentostecnologia-e-pesquisa-075\&Itemid $=965$

CONSELHO FEDERAL DE FARMÁCIA. CFF -Resolução no 585 . Regulamenta as atribuições clínicas do farmacêutico e dá outras providências. CFF, 2013. [Internet] 2013 Ago [citado Ago 26]. Disponível em: http://www.cff.org.br/userfiles/file/resolucoes/585.pdf.

CONSELHO FEDERAL DE FARMÁCIA. CRF. Estudo aponta perfil de intoxicação medicamentosa por automedicação no Brasil. (BRASIL). CRF, 2020. [Internet] 2020 Jun [citado 2020 Set 18]. Disponível em: https://www.cff.org.br/noticia.php?id=5849

CONSELHO REGIONAL DE FARMÁCIA DE SÃO PAULO-CRF-SP. Manual de orientação ao farmacêutico: aspectos legais da dispensação. / Conselho Regional de Farmácia do Estado de São Paulo. -São Paulo: CRF-SP, 2017. Disponível em: http://portal.crfsp.org.br/documentos/crf/Manual-de-orientacao-ao-farmaceutico-ao_versaoWEB.pdf

COSTA, A.L.P. Resistência Bacteriana aos Antibióticos: Uma Perspectiva Do Fenômeno Biológico, Suas Consequências e Estratégias De Contenção. $63 \mathrm{f}$. Trabalho de Conclusão de Curso (Graduação em Biologia) - Curso de Ciências Biológicas, Departamento de Ciências Biológicas e da Saúde, UNIFAP, Macapá, 2016

COSTA, A.L; SILVA, A.C. Resistência bacteriana aos antibióticos e saúde pública: uma breve revisão de literatura. Estação Científica, Macapá. [internet]. 2017 [citado 2020 Jun 19] v.7(2).

ESTRELA, T.S. Resistência antimicrobiana: enfoque multilateral e resposta brasileira. Brasil, Ministério da Saúde, Assessoria de assuntos internacionais de saúde. Saúde e política externa. [citado 2020 Abr 23]; 20: 1998-2018.

FEITOSA, F. P. J. O Papel do Farmacêutico no Controle do Uso Racional de Antibióticos. Curso de Especialização em Assistência Farmacêutica. Crato-Ceará, 2006.

FRANCO J.M, et al. O papel do farmacêutico frente à resistência bacteriana ocasionada pelo uso irracional de antimicrobianos. Semana Acadêmica. Fortaleza, v. I, n. 72, p. I-17, 2015.

GARCIA, J.V.A.S \& COMARELlA, L. O Uso Indiscriminado De Antibióticos E As Resistências Bacterianas. Cad. Sau. e Des [internet]. 2018 [citado 2020 Abr 19]; 13(7). Disponível em: $\quad$ https://www.uninter.com/cadernosuninter/index.php/saude-edesenvolvimento/article/view/1038

GARCIA, R.C. Uso De Antibióticos Prescritos Na Saúde Pública: Revisão Integrativa. [Internet] 2019 [Citado 2020 Jun 17]. 34. TCC (Graduação Em Farmácia) - Universidade Federal Do Mato Grosso, Campus Universitário Do Araguaia, Instituto De Ciências Biológicas E Da Saúde, Barra Do Garças, 2019. Disponível Em: Https://Bdm.Ufmt.Br/Handle/r/1253

GÜELL O. Resistência a antibióticos causa 33.000 mortes por ano na Europa. Impacto desse problema de saúde pública é semelhante ao da gripe, tuberculose e AIDS juntas. Rev. El País. [Internet] 2018 Nov [citado em 2020 Abr 20]: Disponível em: https://brasil.elpais.com/brasil/2018/II/o5/ciencia/1541448787_557623.html

LOUREIRO, R.J; ROQUE, F; RODRIGUES, A.T; HERDEIRO, M.T; RAMALHEIRA, E. O uso de antibióticos e as resistências bacterianas: breves notas sobre a sua evolução. Rev. Port. 
Sau. Pub [Internet]. 2016 Mar [citado2020 Abr 23];34(I):77-84. Disponível em: http://www.scielo.mec.pt/scielo.php?script=sci_arttext\&pid=So870-902520160oorooori\&lng=pt. http://dx.doi.org/Io.1016/j.rpsp.2015.11.003

MARQUES, U.C; DEUSCHLE, R.A; DEUSCHLE, V.C.N. avaliação da prevalência da dispensação de antimicrobianos na farmácia pública do município de cruz alta -RS. Revista Eletrônica de Farmácia. ISSNi8o8-0804 Vol.XII (2), oI-15, 2015.

MUNER L. A importância do farmacêutico no controle e dispensação da morfina conforme a portaria $\mathrm{n}^{\mathrm{o}}$ 344/98 - ministério da saúde. Revista Cathedral [Internet]. 2020 Set [citado 26nov.2020];2(3):187-0o. Disponível em: http://cathedral.ojs.galoa.com.br/index.php/cathedral/article/view/2o6.

O'NEILL J. The Review on Antimicrobial Resistance. Review on Antimicrobial Resistance. p. 2, 2014 .

OLIVEIRA V.B; SILVA T.J. Intoxicação medicamentosa infantil no Paraná. Visão Acadêmica, v. I9, n. I, 2018. Disponível em:https://revistas.ufpr.br/academica/article/view/57576

OLIVEIRA, T.E. A importância do farmacêutico no combate à resistência bacteriana: revisão de literatura [Trabalho de Conclusão de Curso]. Maceió-AL, 2019. Curso de Especialização em Farmácia Hospitalar, Centro Universitário CESMAC, 2019

PAIM R. S. P. \& LORENZINI E. Estratégias para prevenção da resistência bacteriana: contribuições para a segurança do paciente. Rev Cuid [Internet]. 2014 July [citado $2020 \mathrm{Abr}$ 23] ; $5(25)$ ): 757-764. Disponível em: http://www.scielo.org.co/scielo.php?script=sci_arttext\&pid=S2216-09732014000200007\&lng=en. http://dx.doi.org/ro.15649/cuidarte.v5i2.88.

REGINATO F.Z. O uso de antibióticos e o papel do farmacêutico no combate à resistência bacteriana. 2015. 3I f. [Tese] (especialização). Curso de Pós-Graduação Lato Sensu em Gestão de Organização Pública em Saúde, da Universidade Federal de Santa Maria (UFSM, RS). Santa Maria -RS, 2015

ROBINSON, T. et al. Animal production and antimicrobial resistance in the clinic. The Lancet, Nov. 2015.

ROCA I, AKOVA M, BAQUERO F, CARLET J, CAVALERI M, COENEN S, et al. The global threat of antimicrobial resistance: Science for intervention. New Microbes and New Infections, 2015.

ROCHA, A.L. Uso racional de medicamentos. 2014. 49 f. [Trabalho de Conclusão de Curso] Especialização- Instituto de Tecnologia em Fármacos/Farmanguinhos, Fundação Oswaldo Cruz, Rio de Janeiro, 2014.

RODRIGUES AP, DAMBRÓS BP, SANTIN NC, FRIGHETTO M. Análise Das Prescrições De Antibióticos Dispensados Para Crianças Numa Farmácia De Um Município Catarinense. APEvda [Internet]. 2017 [citado 2020 Jun 19]. Disponível em: https://portalperiodicos.unoesc.edu.br/apeuv/article/view/13247

SAMPAIO P.S; SANCHO L.G, LAGO R. F.. Implementação da nova regulamentação para prescrição e dispensação de antimicrobianos: possibilidades e desafios. Cad. saúde colet. [Internet]. 2018 Mar [citado 2020 Nov 25] ; 26( I ): 15-22. Disponível em: 
http://www.scielo.br/scielo.php?script=sci_arttext\&pid=S1414-462X $2018000100015 \& \operatorname{lng}=$ en. https://doi.org/10.1590/1414-462X20180ooro185.

SILVA M \& AQUINO S. Antimicrobial resistance: a review of the challenges in the search for new treatment alternatives. Journal of Epidemiology and Infection Control [Internet]. 2018 Out [citado $2020 \quad$ Nov 8]; 8(4):rop. Disponível em: https://online.unisc.br/seer/index.php/epidemiologia/article/view/ris8o

SILVA, I.M. Antibióticos beta-lactâmicos e as 'superbactérias'. [internet] 2017 [citado 2020 Ago oI]; Dissertação de mestrado. Curso de Mestrado Integrado em Ciências Farmacêuticas; Universidade Lusófona de Humanidades e Tecnologias Disponível em: http://hdl.handle.net/ro437/8903

SINITOX. Sistema Nacional de Informações Tóxico-Farmacológicas. Dados de intoxicação. SINITOX, 2013. [Internet] 2013 [citado 2020 Set 18]. Disponível em:https://sinitox.icict.fiocruz.br/dados-nacionais

SOUZA, C.A. Importância Do Profissional Farmacêutico No Combate A Automedicação [trabalho de conclusão de curso] 2017. 29 f. Graduação em Farmácia - Faculdade de Ciências Humanas, Biológicas e da Saúde de Primavera do Leste, Universidade de Cuiabá - UNIC, Primavera do Leste - MT, 2017.

SOUZA, R.H. O Controle De Antimicrobianos: O Que Podemos Esperar? [Monografia]. Rio Verde- GO, 2016. Graduação em Farmácia, Faculdade de farmácia, da Universidade de Rio Verde - UniRV - Campus Rio Verde, 2016.

VIEIRA D.M.; CAVEIÃO C. Perfil das intoxicações medicamentosas no estado de São Paulo no período de 1999 a 2012 na perspectiva da vigilância sanitária. Revista Saúde e Desenvolvimento. [Internet] 2016 [citado Ago 23] v.9,(5),p.II9-I4. Disponível em: http://www.uninter.com/revistasaude/index.php/saudeDesenvolvimento/article/view/521

WORLD HEALTH ORGANIZATION, 2015. Global Action Plan on Antimicrobial Resistance. Worldwide country situation analysis: response to antimicrobial resistance. WHO, 2015. [internet].2015. Abr [citado $2020 \mathrm{Abr} 20$ ]. Disponível em: https://apps.who.int/iris/bitstream/handle/ro665/r63468/9789241564946_eng.pdf?sequence=I.

WORLD HEALTH ORGANIZATION. The Rational use of drugs: re-port of the conference of experts. WHO; 1987. Nairóbi, 25-29 november 1985. Geneva. 